\title{
Why is it Difficult to Oust Violence from Correctional Institutions?
}

\author{
Marzanna Farnicka*
}

Department of Psychology, University of Zielona Góra, Poland

\begin{abstract}
The paper focuses on the educational system for the future prison staff that is chiefly based on a dedicated university course, i.e. rehabilitation. The paper presents differences between students and problems arising from their inherent properties, being greater readiness for aggression and approval of aggression. The presented study was aimed at verifying the hypothesis on the relationship between perceived conditionings of aggressive behaviours and personal experience of being a victim or an aggressor together with the attitude towards it and the chosen occupational role. The studied group consisted of 79 students. The research tools were Mini - DIA, The Buss-Perry Aggression Questionnaire and the Inventory of Social and Moral Approval of Interpersonal Aggression were also used. The results obtained indicate different determinants for persons involved in perpetration or victimization and for those displaying low levels of such behaviour. It was assumed that people majoring in rehabilitation more often assume the role of an aggressor or a victim than students majoring in other disciplines. Research findings were supposed to contribute to developing a prevention model among students and other people working in the field of violence and violence handling, as well as to emphasise the need to reflect upon and possibly change personal attitudes towards these behaviours.
\end{abstract}

Keywords: Approval of aggression, readiness for aggression, violence legitimacy, violence of prison staff.

\section{INTRODUCTION}

Many researchers highlight the link between social values and orientations and workplace power relations and the way job duties are followed. The question that is now being posed is to what an extent prisons, which are by definition confined and founded on violence and coercion (exerted by the society and law upon an individual), should ban and dismiss prevailing methods of supervision and the resulting reward or penalty. Despite guidelines to employ softer methods of impacting prisoners, one can observe that prison staff across Poland continues to dehumanise and treat inmates as inferior (Herberger, Magda, 2014). These behaviours can be seen either as a strategy for handling failures, frustration or the effect of burnout. Based on studies by Leyman and Gustafsson (1996) and Randall (1997), Zimbardo (1973) views prison staff as particularly disposed to aggression and violence in relations. All earlier attempts at reforming the prison system have focused on staff training, turning closed prisons into half-open institutions and staff teaching.

An interesting issue is the moment when violence starts to be noticed. Quite often there is a trigger moment when it is revealed. Before that, aggressive or humiliating behaviours are treated as manifestations of independence or a specific range of behaviours. Once violence is revealed, the reasons start to be analysed. Here are some examples of the attribution: 'aggression is a normal phenomenon in prisons',

*Address correspondence to this author at the Department of Psychology, University of Zielona Góra, Poland, Member of Polish CICA Committee; Tel: +420 721648 234; E-mail: marzanna@farnicka.pl 'violence has always existed and will be in this kind of institutions'. Unconscious and social determinants of behaviours and relations between convicted inmates and guards have been revealed in a widely known Zimbardo's prison experiment (1973). There is a debate going on in Poland at the moment on introducing a violence ban in correctional institutions. My research domain focuses on a hypothesis that people with higher aggression rate and violence approval are preferred in the recruitment to jobs involving clear-cut power hierarchy.

The available research studies into undertaking the role of an aggressor or a victim treat readiness for aggression as a phenomenon comprising of the emotional and moral component and relatively stable temperament traits, and point to the significance of such variables as self-esteem, level of self-control, sex, family background and parental role handling along with personal experience (Björkqvist, 1994; Björkqvist, Osterman, \& Lagerspetz, 1994; Crick and Rose, 2000, Dettinger, Hart, 2007; Frost; Stearns, 1993, Ramirez, Andreu and ell., 2007). Numerous empirical studies show that differences in approving aggressive behaviours can be seen not only against the backdrop of social and cultural background, but also sex (Alvarado, Ramirez, 2014; Archer, 2004; Bem, 1993, Frączek 1985; Frączek et. al. 2009; Huesmann, Guerra 1997; Lagerspetz, Westman, 1980). Thus, differences in the approval of aggressive behaviours, both verbal and physical, between sexes and majors chosen at university were expected. The highest degree of approval of aggression in its extreme form (tortures, assault and killing) was expected from males majoring in rehabilitation, i.e. a university course that focuses on working with people who had seriously breached 
the accepted social and legal standards and are either confined in closed and total institutions or on probation, yet remain under constant supervision (Ramirez, 1993).

The results found by (Maxwell and Visek 2009), as well as by Lagerspetz and her collaborators (1988) indicate that taking up roles involving aggressive law enforcement, such as a police officer or a soldier, involves greater approval/tolerance for aggressive behaviours. The lowest tolerance for such behaviours was expected from a group of females in physical education, for which aggressive behaviours may be a part of rivalry or a pedagogical concern. Women were expected to reveal a greater emotional component than men along with approval of behaviours involving emotionally-regulated aggression (annoyance, threats and fury). In the latter case, top results were expected from females, and not from males (in particular females majoring in rehabilitation).

The presented study was aimed at verifying the hypothesis on the relationship between taking up roles involving aggressive law enforcement, such as a police officer or a soldier and greater approval/tolerance for aggressive behaviours (hypothesis I). This aspect has been studied before (Farnicka, Liberska, 2013), however, the study group found there was smaller and the respondents had not been introduced to the research situation through indicating their future professional career. It was assumed that people majoring in rehabilitation would more often assume the role of an aggressor or a victim than students majoring in other disciplines (hypothesis II).

The underlying assumption of the present study is that independent variables comprise of situational setting properties and personal resources in a given situation. Situational factors included: a) place where the study was held (relatively high approval of aggressive behaviours in Poland, in particular for its manifestations); and b) major, which reveals different approach to aggression and aggressive behaviours. From the perspective of rehabilitation, the latter is considered has a potential breach of rules, whereas physical education teachers approach aggression as a trigger for player's development and rivalry. For this reason, the control group included physical education students who might have had similar experience and attribution of aggressive behaviours (importance of rivalry and power relations), yet have different career prospects in the future. Investigated personal resources included: age and sex, perception of reasons for aggressive behaviours and personal experience related to being a victim or an aggressor in such behaviours.
Therefore, the investigative procedure was supposed to provide an answer to the question of whether there were any differences between students majoring in rehabilitation and other disciplines in their level of readiness for aggression and approval of aggression.

\section{MATERIALS AND METHODOLOGY}

In this study, readiness for aggression was measured with the IGAI questionnaire from 2008 by Adam Frączek, Karolina Konopka and Marek Smulczyk. The inventory consists of 30 items measuring three types of readiness for interpersonal aggression, i.e. emotional-impulsive (E-I), habitual-cognitive (N-P) and personality-immanent (O-I). Reliability factors for the scales are: 0.715 for E-I scale, 0.798 for N-P scale and 0.695 for O-I scale.

To measure social and moral approval of interpersonal aggression, the Inventory of Social and Moral Approval of Interpersonal Aggression was used (Frączek, Dominiak Kochanek, Kulawska, 2009, upon authors' consent). It is based on the Polish adaptation of the Questionnaire of Social Attitudes (Lagerspetz and Westman, as revised by Frączek, 1985) and the Questionnaire of Moral Attitudes to Aggression (Cuestionario des Actitudes Morales sobre Agresion, Ramirez, 1985). The inventory includes 6 circumstances (self-defence, defence of another person, failure to come to an agreement, anger, defence of one's property and punishment), for which the respondent is supposed to rate the degree of approval of different forms of aggression (irony, manifesting anger, threats, assault, torture and killing) using a three-point scale showing approval of the aforementioned behaviours: never, sometimes and always.

To investigate personal experience as violence perpetrator or a victim, the Mini-DIA method by OstermanBjorkvist (2008) was used.

The study covered 142 people over 19 years (average age being 23.5). Given the fact that there was an imbalance in the number of people, rehabilitation students were selected at random to create the second study group with equal representation of males and females as well as students majoring in two different disciplines (see Table 1). Prior to the study, respondents were asked to tell what their major was and briefly discuss its nature. The limitation of the study group by the random selection reduced the number participants, but was considered to be one of the best ways to do in case a different number of people in sub - groups.

Table 1. Study Group.

\begin{tabular}{|c|c|c|c|c|c|}
\hline \multicolumn{3}{|c|}{ First Group } & \multicolumn{3}{c|}{ Final Study Group } \\
\hline & Rehabilitation & Physical Education & Rehabilitation & Physical Education & Total \\
\hline \hline Females 98 & 76 & 22 & 20 & 20 & 19 \\
\hline Males 44 & 25 & 19 & 20 & 39 & 79 \\
\hline Total 142 & 101 & 41 & 40 & 39 \\
\hline
\end{tabular}




\section{RESULTS}

The Relationship between Sex, Chosen Major, the Level of Approval of Aggression and Readiness for Aggression

The analysis of differences within the group depending on sex of respondents revealed discrepancies between females and males in terms of their readiness for aggression in the emotional-impulsive domain. Women showed greater readiness in this variable $(\mathrm{M}=0.64$, Stand. $\mathrm{dev}=0.25)$ than males $(\mathrm{M}=0.326$, Stand. $\mathrm{dev}=0.266$, relevance $\mathrm{t}=3.794$, $\mathrm{df}=37, \mathrm{p}<0.001)$, regardless of what their major is. Based on mean comparisons, studied males showed greater readiness in the habitual-cognitive domain $(\mathrm{M}$ females $=0.262$, Stand . $\operatorname{dev}=0.21, \mathrm{M}$ males $=0.46$, Stand. $\operatorname{dev}=0.241, \mathrm{t}=-2.778$, $\mathrm{df}=37, \mathrm{p}<009)$. The analysis of differences connected to chosen major reveals that rehabilitation students have a significantly higher level of readiness for aggression in the personality-immanent domain ( $\mathrm{M}$ rehab $=0.185, \mathrm{SD}=0.14$, $\mathrm{M} \mathrm{pe}=0.105, \mathrm{SD}=0.097, \mathrm{t}=2.032, \mathrm{df}=2, \mathrm{p}<0.049)$ and the degree of irony approval $(\mathrm{M}$ rehab $=2.375, \mathrm{SD}=044, \mathrm{M}$ $\mathrm{pe}=2.01, \mathrm{SD}=0.357, \mathrm{t}=2.822, \mathrm{df}=37, \mathrm{p}<0.009)$.

According to obtained results and in line with the expectations, females revealed a tendency of readiness for aggression in the emotional sphere, whereas males did it in the habitual domain. No differences have been identified among sexes in the degree of approval of aggressive behaviours.

Rehabilitation students revealed a higher degree of approval of aggressive behaviours in the form of irony in all situations. Their level of readiness for aggression in the personality-immanent domain was also higher. It means that, in line with my assumptions, the choice of a major made by these people further reinforces certain personality traits which can be seen in the greater approval of irony, which in turn is a prerequisite for aggressive behaviours. This correlation holds true only for rehabilitation students.

The Relationship between Personal Experience in Undertaking the Role of an Aggressor or a Victim and the Chosen Major

Study results revealed a significant difference between rehabilitation and physical education students in the frequency of undertaking the role of a verbal aggressor $(\mathrm{M}$ rehab $=1.8, \mathrm{SD}=0.69, \mathrm{M}$ pe $=1.66, \mathrm{SD}=0.71, \mathrm{t}=2.635$, $\mathrm{df}=36, \mathrm{p}<0.012$ ). Furthermore, a correlation was identified between the revealed approval of aggression and undertaking the role of a verbal aggressor among rehabilitation students (Pearson's $r=0.465, p<0.01$ ). No such correlation was found for physical education students (Pearson's $r=-0.417, p>0.1$ ). This finding may suggest that rehabilitation students give unique consent to employing aggressive behaviours founded on the approval of aggressive behaviours, irony in particular. It must be remembered that irony includes the anger component and is presented in an acceptable form.

\section{DISCUSSION}

Study findings were supposed to contribute to developing a prevention model for students and other people who work in the field of violence and violence handling, as well as to emphasise the need to reflect upon and possibly change personal attitudes towards these behaviours. The choice of major has been considered as a product of recognising one's personal disposition and personality aspects that may be further developed along the educational path.

The study was exploratory in nature and has confirmed that psycho-social factors play a crucial role in career choice. The obtained results helped picture the nature of difficulties involved in changes in adopting the role of prison officer and elements shaping the professional identity.

The presented study has its limitations, however (eg. simply statistics analyses). But the problem is addressed primarily before the job is taken up, when one prepares for the future career. Cross-sectional or longitudinal comparisons would reveal the dynamics of changes, both individual and cohort. However, result analysis has shown that in the study group there are indications for both a special diagnosis of people who study rehabilitation and a special training to confront social insight and evaluation of violent behaviours in the career perspective. Further investigation of these aspects may bring interesting results concerning determinants of aggressive behaviours in prison environment.

Findings of studies that have been carried out so far indicate that this process (of recognising and adapting to new workplace environment, even if only imaginary) is different and non-uniform in males and females, and is connected with imagined ways of role performance, social insight and resulting attitudes (approval of aggressive behaviours) together with cognitive factors (situation recognition, e.g. hostility) and emotional ones (e.g. anger). Emerging aggressive behaviours (that manifest them when undertaking the role of either a victim or an aggressor) should be considered content and manifestation of the interaction of all factors along with the support system developed for a given occupational role. Preparing one for a given role and performing it is also based on the choice between being oneself as an independent entity and being oneself as a dependent entity together with others. Such understanding is in line with the approach of the theory of socialisation to occupational roles and personal preferences in career choice (Konopka, Dominak - Kochanek, 2012, Wojciszke 2010).

The implications of these choices, which are actually being made not at work but in the course of individual's development also at university, require that the individual recognises their dispositions in their daily activities, defines priorities and selects personal development strategy. It is often the case that professional development (in early adulthood in particular) requires one to reject earlier authorities and confront their own past and previous behavioural patterns along with social references. That is because goals and norms of a group often determine the behaviour of its members, while the degree of compliance is the basis for self-identification. Thus, the occupational group (imaginary or real life) may become a miniature social world of its own.

Therefore, the findings that reveal differences between rehabilitation students and other students point to the presence of social insight that drives people with increased 
readiness for aggression to take up this particular university course. As it is the case that people choosing rehabilitation as their major at university were characterised by different (greater) readiness for aggression in the personalityimmanent domain. Furthermore, it has been noticed that annoyance approval in this group is correlated with more frequent assumption of the role of a verbal aggressor. Differences between females and males in the group of rehabilitation students and the group of physical education students should be strongly emphasised here. In all situations, rehabilitation students revealed a higher degree of approval of aggressive behaviours taking the form of irony. Their readiness for aggression was also greater in the personality-immanent domain. It means that, in line with my assumptions, the choice of a major made by these people further reinforces certain personality traits which can manifest themselves in greater approval of irony, which in turn is a prerequisite for aggressive behaviours. This correlation holds true only for rehabilitation students. The findings that have been made may indicate that both females and males can cause violence in a workplace setting. It has already been reported by researchers (Olweus, 1979; Perry, Schmidtke Kulig,1993) yet the resulting insight is hardly ever analysed in job interviews. Until recently, there had not been any female officers in the Polish prison system, and their introduction was supposed to reduce violent behaviour rates. The results of this and earlier studies show that their presence brings new challenges for designers of care and supervision schemes for confined prisoners or those on probation.

Moreover, what deserves special attention is the experience of people who decide to study rehabilitation at university. The fact that they are more eager to undertake the role of a physical aggressor means that they welcome resorting to violence (within the limits of the law) in order to achieve their goals. These findings reveal a certain orientation towards violating the boundaries of others. The correlation found in this group between irony approval and the frequency of violating the boundaries of others by way of verbal aggression indicates that they assume the right to such behaviour. This may well be connected with the sense of legitimacy of this form of aggression (social insight), yet may as well show a tendency for perceiving others as inferior (not me $=$ you, but power relation and devaluation). This tendency should be further analysed given the fact that rehabilitation is a discipline within pedagogics, and as such treats the relationship between a correctional officer and an inmate as one that involves development, original approach and coaching. Essential here are hence results of earlier research showing links between the image teachers hold and the teaching environment they create and the frequency of violence between them and those in their care.

\section{CONCLUSION}

According to our results rehabilitation students prefer vertical hierarchy of power and clear-cut systems. Students majoring in rehabilitation may be closer to jobs such as police officers and soldiers than teachers. The study showed that in order to support people whose work involves/will involve solving conflicts and prevention of aggressive behaviors and disorders (students of rehabilitation, prevention, physical education, social workers and family assistants), we should show them a link between their own experience, personality (readiness for aggression), their tolerance of aggression and ability to take preventive or interventional measures, and solve conflicts. This could be done in a cognitive way and by means of training and practice to take care of their development and value in their work.

\section{CONFLICT OF INTEREST}

The author confirms that this article content has no conflict of interest.

\section{ACKNOWLEDGEMENTS}

None declared.

\section{REFERENCES}

Alvarado, J.M., Ramirez J. M. (2014). Aggression, Pleasure, and Cognitive Dissonance, The Open Psychology Journal, 7, 50-56

Archer, J. (2004). Sex differences in aggression in real-world settings: A meta-analytic review. Review of General Psychology, 8(4), 291

Bem, S. L. (1993). The lenses of gender: Transforming the debate on sexual inequality. New Haven, C.T.: Yale University Press

Björkqvist, K. (1994). Sex differences in physical, verbal, and indirect aggression: A review of recent research. Sex Roles, 30(3-4), 177188.

Björkqvist, K., Osterman, K., \& Lagerspetz, K. M. (1994). Sex differences in covert aggression among adults. Aggressive Behavior, 20(1), 2733 .

Crick, N. R., \& Rose, A. J. (2000). Toward a Gender-Balanced Approach to th e Study of Social-Emotional Development A Look at Relational Aggression. Toward a feminist developmental psychology, 153.

Dettinger, S., \& Hart, G. (2007). The relationship between self-esteem and indirect aggression in the workplace. Journal of Psychiatry and Psychology, 1(1), 337-347.

Farnicka M., Liberska H. (2013). The Relationship Between Attribution and the Level of Approval of Aggressive Behaviours-The Polish Study, Psychology Study, 3, 687-693.

Frączek, A. (1985). Moral approval of aggressive acts. A Polish-Finnish Comparative Study. Journal of Cross-Cultural Psychology,16(1), 41-54.

Frączek, A., Konopka, K., \& Smulczyk, M. (2008). Readiness for interpersonal aggression inventory. Adam Frączek, Instytut Psychologii Stosowanej, Akademia Pedagogiki Specjalnej im. Marii Grzegorzwskiej, Warszawa, APS

Frączek, A., Dominiak-Kochanek M., Kulawska, E. (2009). The Inventory of Social and Moral Approval of Interpersonal Aggression, Warsaw: APS

Frost, W. D., \& Averill, J. R. (1982). Differences between men and women in the everyday experience of anger. In Anger and Aggression (pp. 281-316). Springer New York.

Herberger J., Magda E. (2014). Prison staff aggression and its determinants - Poster during XXXVII CICA Developmental and Social Conditionings of Aggression, 22-25 June, Zielona Góra, Poland

Huesmann, L. R., \& Guerra, N. G. (1997). Children's normative beliefs about aggression and aggressive behavior. Journal of Personality and Social Psychology, 72(2), 408.

Konopka, K., Dominiak-Kochanek, M. (2012). Orientacja edukacyjna a wzorce gotowości Ruch Pedagogiczny, 3, 69-84

Lagerspetz, K. M. J., \& Westman, M.(1980). Moral approval of aggressiveacts: A preliminary investigation. Aggressive Behavior, $6,119-130$.

Lagerspetz, K. M., Björkqvist, K., \& Peltonen, T. (1988). Is indirect aggression typical of females? Gender differences in aggressiveness in 11-to 12-year-old children. Aggressive Behavior, 14(6), 403-414.

Leymann, H., \& Gustafsson, A. (1996). Mobbing at work and the development of post-traumatic stress disorders. European Journal of Work and Organizational Psychology, 5(2), 251-275. 
Maxwell, J. P., \& Visek, A. J. (2009). Unsanctioned aggression in rugby union: Relationships among aggressiveness, anger, athletic identity, and professionalization. Aggressive Behavior, 35(3), 237-243.

Olweus D., (1979). Stability of aggressive reaction patterns in males, Psychological Bulletin, 86,852-875

Osterman, K., \& Björkqvist, K. (1998). The mini direct indirect aggression inventory. Finland: Abo Akademi.

Perry E.L., Schmidtke, J. M., Kulig C.T. (1998). Propensity to sexually harass: an exploration of gender differences. Sex Roles, 38, 443460.

Ramirez, J. M. (1985). Similarities in attitudes toward interpersonal aggression in Finland, Poland and Spain. The Journal of Social Psychology, 131, 737-739.
Ramirez, J. M. (1993). Acceptability of aggression in four Spanish regions and comparison with other European countries. Aggressive Behavior, 19, 185-197.

Ramirez, J. M., Andreu, J. M., Fujihara, T., Musazadeh, Z., \& Saini, S. (2007). Justification of aggression in several Asian and European countries with different religious and cultural background. International Journal of Behavioral Development, 31, 9-15.

Randall, P. (1997). Adult bullying. London: Routledge.

Wojciszke, B. (2010). Sprawczość i wspólnotowość, Gdańsk GWP

Zimbardo, P. G. (1973). On the ethics of intervention in human psychological research: With special reference to the Stanford prison experiment. Cognition, 2(2), 243-256.

(C) Marzanna Farnicka; Licensee Bentham Open.

This is an open access article licensed under the terms of the Creative Commons Attribution Non-Commercial License (http://creativecommons.org/licenses/ by-nc/3.0/) which permits unrestricted, non-commercial use, distribution and reproduction in any medium, provided the work is properly cited. 